\title{
Energy Shocks and Macroeconomic Stabilization Policies in an Agent-based Macro Model
}

Sander van der Hoog and Christophe Deissenberg

\begin{abstract}
In this chapter we consider the effects of exogenous energy shocks on an agentbased macroeconomic system and study the out-of-equilibrium dynamics. We introduce automatic stabilizers that allow the artificial economy to absorbe the shocks. Two types of macroeconomic stabilization policies are implemented: a consumer subsidy scheme that compensates households for their loss in purchasing power, and a tax reduction scheme that affects both households and firms to support consumption and investments. Policy experiments are then carried out to evaluate the effectiveness of these macroeconomic policies. Finally, we are able to distinguish between short- and long-term effects of the policy measures.
\end{abstract}

Key words: Agent-based macroeconomics, energy shocks, stabilization policies.

JEL codes: C61, C63, D51, E27, E63.

Sander van der Hoog

Dept. of Business Administration and Economics, Bielefeld University, Universitätsstrasse 25, D33615 Bielefeld, Germany, e-mail: svdhoog@gmail . com

Christophe Deissenberg

GREQAM, Universitée de la Méditerranée II, Château Lafarge, Route des Milles, 13290 Les Milles, France, e-mail: christophe.deissenberg@univmed.fr 


\section{Introduction}

The variation of energy prices has substantial effects on the economic activity in a region affecting real output, economic growth and employment among other key variables. Rotemberg and Woodford (1996) for example estimate using U.S. data that a $10 \%$ increase in oil prices leads to an output decline of $2.5 \%$ after five or six quarters. Actual increases in energy prices, however substantially exceed such percentages as demonstrated in Figure 1. The figure shows the real energy price behavior during the 2008 energy crisis. The price of Brent crude oil went up by $390 \%$ between 2002 and July 2008, which translates to a monthly increase of $2 \%$. Then it went sharply down by $-76 \%$ between July 2008 and Jan 2009, which implies a monthly decrease of $-22 \%$. When the crisis was over at the beginning of 2009 the price was basically back at its original level of 2002 .

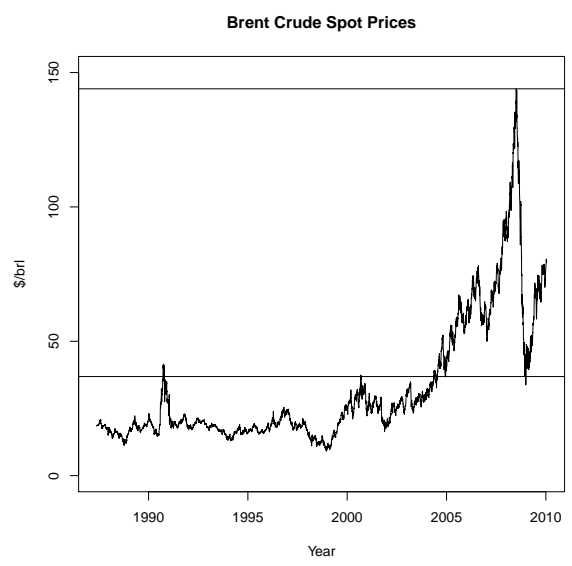

Fig. 1 May 1987 - Jan 2010 daily Brent spot prices. Source: Energy Information Administration. Horizontal lines indicate the top in 2002 (36.87USD) and the top in July 2008 (143.95USD).

For an economy like the EU, which to a large extend depends on the supply of relevant factors like oil from the outside, variations in the price of energy can be seen as exogeneous shocks affecting the economic dynamics within the EU. An important policy question in this respect is how the implications of such energy shocks can be alleviated by the appropriate choice of policy measures to be introduced in response to a shock.

Using the agent-based macroeconomic model that we have developed one can study such questions in relatively great detail. Since we have microscopic data at the level of individual households, firms and the government, the model provides us with a testbed, a computational laboratory, in which we can do 'What-if' analyses for such a policy measure and compare the effects between different scenarios. 
In our computational experiments we focus on the use of two types of stabilization policies to mitigate the negative effects of energy shocks to the macroeconomy: (i) a consumer subsidy that only affects households, (ii) an income tax reduction that affects both households and firms (personal income and corporate income).

These policies are used to counteract the effects of energy shocks on the GDP growth rate, unemployment and inflation by directly stimulating consumption, employment and investment.

A direct motivation to study the tax reduction policy is that in many developed countries fuel taxes form a large part of the final fuel price, and the revenues from these taxes serve to finance public infrastructure (road maintenance for example). One measure used in the past to avoid the negative impacts of oil shocks is then to temporarily or permanently suspend these taxes as fuel costs are rising, as occurred in 2000, when France, Italy, and the Netherlands lowered fuel taxes in response to protests over high diesel and gasoline prices.

The remainder of the chapter is organized as follows. In Section 2 we describe the model, the agents and their behavioral repertoires. We also describe the stabilization policies and the setup of the computational experiments. Section 3 presents the simulation results and Section 4 concludes.

\section{The model}

\subsection{General features}

Here we can only briefly recapitulate the main features of the underlying model that was developed over a period of three years in the EURACE project. ${ }^{1}$ For more details on its implementation, the interested reader is referred to the following papers.

A general overview of the model and a discussion of the computational issues can be found in Deissenberg et al. (2008). The core of the model is explained in Dawid et al. $(2008,2009)$, with formal descriptions of the production decisions in the consumption and investment goods sectors, the recruitment and wage setting mechanism on the labour market, and households' consumption and savings decisions.

A description of the financial market where households can trade firm stocks and government bonds is found in Raberto et al. (2008a,b). Finally, the financial management of the firm describing the financing of production and linking the real side of the economy to the financial sphere is found in van der Hoog et al. (2008).

Putting all the pieces together, we obtain an agent-based model of a fully integrated macroeconomic system, consisting of two real sectors for consumption and investment goods and a financial sector consisting of a credit market and an asset

\footnotetext{
${ }^{1}$ For more information on the EURACE Project, see www. eurace. org.
} 
Table 1 Agent population.

\begin{tabular}{ll}
\hline \hline Agent & Number \\
\hline Households & 1600 \\
CGFirms & 80 \\
IGFirms & 1 \\
Banks & 2 \\
Government & 1 \\
Malls & 1 \\
Eurostat & 1 \\
Central Bank & 1 \\
Clearinghouse & 1 \\
\hline \hline
\end{tabular}

market. The model also contains a public sector consisting of a government, a central bank, and a statistical office that collects microdata and generates macrodata.

The part of the model described here could be viewed as a missing link since it describes an exogenous energy market that constitutes a proxy for the link to the 'rest-of-the-world' by affecting the production costs of the investment goods producers. Using this exogeneous energy market we can study the out-of-equilibrium dynamics that follow from energy shocks.

\subsection{The agents}

The model consists of 'active' agents and 'passive' agents, who provide auxiliary functions for information aggregation and dissemination such as data collection, intermediation between buyers and sellers, or they act as handles for affecting macroeconomic policy.

The active agents are: Households (1600), CGFirms (80 consumption goods producers), IGFirms (1, investment goods producers), Banks (2), and Governments (1). These agents all have a behavioral repertoire and interact, either directly or indirectly, on the various markets that make up the system.

The passive agents are: Malls (1, providing a local market for consumption), Eurostat (1, collecting data, distributing aggregate statistics), a Central Bank (1), and a Clearinghouse (1). The passive agents do not make any decisions.

Table 1 contains information on the types and numbers of agents in the artificial economy.

\section{Households}

The main features of household behavior are summarized by these decisions:

- Employment decision: unemployed households/workers read vacancies from all firms, taking into account the wage offer and their own reservation wage. 
- Consumption/savings decision: at the beginning of each month, households allocate a budget for consumption and savings (further divided between a savings account and an asset portfolio) that is modelled according to empiricallyfounded rules, as in Deaton $(1991,1992)$. The consumer $k$ sets its consumption budget for the coming month by the rule:

$$
\begin{aligned}
B_{k, t}^{\text {cons }} & = \begin{cases}\operatorname{Liq}_{k, t}^{\text {avail }}-\kappa \Delta, & \Delta>0 \\
\operatorname{Liq}_{k, t}^{\text {avail }}, & \text { otherwise. }\end{cases} \\
\Delta & =\left(\operatorname{Liq}_{k, t}^{\text {avail }}-\theta \operatorname{Inc} c_{k, t}^{\text {Mean }}\right)
\end{aligned}
$$

Here $\operatorname{Liq}_{k, t}^{\text {avail }}$ is the available liquidity (called cash-on-hand in Deaton (1991, 1992), consisting of all liquid or near-liquid assets) and $I n c_{k, t}^{\text {Mean }}$ is the mean disposable income over the previous four months. $\Delta$ represents a buffer stock of liquidity in excess of the mean income, and the propensity to save satisfies $0<\kappa<1$. The parameter $0<\theta \leq 1$ is a characteristic of the household, and represents the fraction of mean income that determines the size of the buffer stock. If the available cash-on-hand falls below the buffer stock $\left(\operatorname{Liq}_{k, t}^{\text {avail }}<\theta \operatorname{Inc} c_{k, t}^{\text {Mean }}\right)$, the household will not save anything and spend all cash-on-hand on consumption. If $\Delta$ is positive, there are positive savings as well.

- Selection of consumption goods: once a week a household visits a shopping mall located in its own region, where firms offer goods at local prices. The decision from which firm to buy (at the local mall) is based on a discrete-choice logit model, taking into account the prices offered by all firms that sell goods at the local mall.

- Financial decisions: households' asset portfolio allocation decisions are based on Prospect Theory (Kahneman and Tversky, 1979), see Raberto et al. (2008a,b) for further details.

\section{Investment goods producers}

In the basic setup of the model, there is only one single investment goods producer (IGFirm) who acts as a global supplier of investment goods (machinery). All firms producing consumption goods purchase their capital goods from this machine manufacturer. The profits of this single manufacturer are channelled back into the economy and distributed as dividends to the households. Each household is assumed to hold equal shares in the IGfirm.

The main features of the behavior of the investment goods producer are summarized by:

- Investment goods are produced on demand and without rationing and are produced using only energy as an input.

- Innovation process: Every period with probability $\gamma^{i n v} \in(0,1)$ an innovation leads to an increase in the quality of the capital good, and with probability $\left(1-\gamma^{i n v}\right)$ there is no change in quality. 
- Technological progress: The productivity of the investment good increases as a function of its quality. A succesful innovation leads to an increase in productivity of newly produced capital goods by a fixed percentage $\Delta q^{i n v}$.

- Pricing decision: The price of investment goods $p^{i n v}$ increases with the same rate as the quality level.

\section{Consumption goods producers}

The main features of the behavior of consumption goods producers are summarized by these decisions:

- Production decision: output is planned based on the current inventory levels at the malls, and a standard stock replenishment rule that can be found in the operations research and management literature (see e.g. Hillier and Lieberman (1986)). In addition, there is production smoothing in order to prevent the output of the firm to fluctuate excessively.

- Employment decision: the planned labour force is directly related to the planned production quantity, and to the current technology of the capital stock. If additional workers are needed vacancies are opened, or workers are fired if the opposite is the case. The search and matching algorithm is described in detail in Dawid et al. (2009).

- Investment decision: The existing capital stock depreciates and needs to be upgraded if the firm wants to benefit from the productivity increase of newly produced capital goods. Investments follow from a planned or desired capital stock (expansion plus replacment of depreciated old stock).

- Financing decision: To finance the production plan, firms follow a hierarchical decision-making routine. The first least risky choice is to resort to internal financing. If internal liquidity is insufficient, firms apply for external funding. They first visit the credit market to apply for bank loans. If they experience credit constraints, the next step is to issue new equity (shares) on the asset market. If this still does not suffice then the production plan is revised, and the planned investment, planned labour force, and planned output are all scaled down until it is possible to finance the new production plan. See van der Hoog et al. (2008) for details.

- Pricing decision: the price of consumption goods is determined using a mark-up pricing routine based on 'break-even analysis' (see Nagle, 1987).

- Dividend payout decision: If the firm makes positive profits, it pays out dividends to its shareholders. The dividend decision is to maintain a constant dividend to earnings ratio. This choice of behavioral rule is based on survey data provided in Allen and Michaely (2004) and Brav et al. (2005). 


\subsection{Time scales and activation regimes}

Agents' actions are event-based or time-based, where the latter can follow either subjective or objective time schedules. Economic activities take place on a hierarchy of time-scales: yearly, monthly, weekly and daily activities all take place following calender-time or subjective agent-time. Agents are activated asynchronously according to their subjective time schedules that is anchored on an individual activation day. These activation days are uniformly randomly distributed among the agents at the start of the simulation, but may change endogenously (e.g., when a housheold gets re-employed, its subjective month gets synchronized with the activation day of its employer due to wage payments). Figure 4 provides a pseudocode of the economic activities taking place at various time-scales.

In the next section we explain how we include energy shocks into the basic model.

\subsection{Capturing an energy shock in the model}

We now enrich the model by including the impact of increases in the price of energy on the production costs of the investment goods producers.

As was already briefly outlined in the introduction, the energy shocks enter the model through a multi-stage process. Investment goods are produced using energy as the only input. During an energy crisis the costs of energy increase, leading to an increase in the production costs of the producers of investment goods. This increase in production costs enters into the pricing of the investment goods through an energy price mark-up, and then enters into the production costs of the producers of consumption goods. At the final stage, the consumption goods producers incorporate the increase in their price for the consumption goods, again by using a mark-up pricing routine, which leads to an increase in the consumer prices.

We typically assume that an energy crisis consists of a succession of consecutive, identical (in length and intensity) energy price increases. Thus, an energy crisis is captured by three parameters: the intensity of the single price increases $(\pi)$, their periodicity $\Pi$ (the number of days between two consecutive price increases), and the number of price increases $(n)$. The total duration of the energy crisis $(d)$ is then $d=\Pi n$. The price increase $\pi$ is assumed to instantaneously disappear at the end of the total duration. The time profile of a typical energy crisis is illustrated in Figure 2 .

The energy costs of the investment goods producers are incorporated into the price of the capital good by an energy price mark-up that equals the intensity of the price shock $(\pi)$ :

$$
p_{t+1}=\left(p_{t}+p_{t, c}\right)(1+\pi),
$$

where $p_{t}$ is the price in period $t$ and $p_{t, c}$ is the price update due to the stochastic process of productivity increases (technological innovations). 


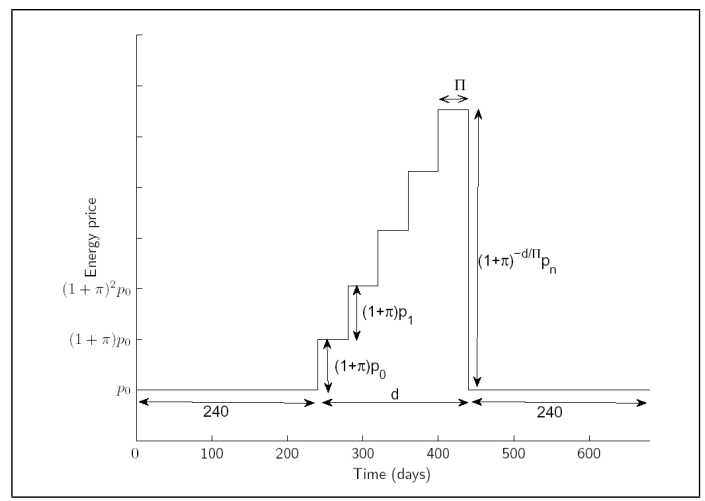

Fig. 2 The time profile of an energy shock experiment.

The additional revenues stemming from the technologically motivated price increase $p_{t, c}$ are partly paid out as taxes and partly paid out as dividends to households.

The revenues that accrue due to the energy costs mark-up $(\pi)$ are not paid out in taxes or dividends. Instead, the money is stored in a variable that represents the total cumulative income of the owners of the energy source (the Sheik of Qatar, Dubai, Russian oligarchs), which does not play any role in the economic dynamics. In other words, it leaves the economic system.

\subsection{The consumer subsidy policy}

The consumer subsidy is meant to compensate households for their loss in purchasing power. The objective is to support the demand side of the economy. Therefore each household receives a subsidy that is a percentage of its total monthly consumption expenditure. The subsidy percentage is determined at the end of each year. The individual subsidies are computed at the end of each month, after the household knows its total consumption expenditures. The Government thus acts with a yearly frequency, while households act on a monthly basis.

\section{Policy activation}

The consumer subsidy is activated as a function of the GDP growth rate $X_{t}$ (annualized growth, measured monthly) by using two trigger levels: an ON trigger $a$ and an OFF trigger $b$, with typically $a<b$. The subsidy becomes active whenever the GDP growth rate falls below $a\left(X_{t}<a\right)$, and is switched off again as soon as the growth rate is above $b\left(X_{t}>b\right)$. 
The magnitude $S_{t}^{h}$ of the subsidy given to household $h$ is determined by:

$$
S_{t}^{h}= \begin{cases}-C_{t}^{h}\left|X_{t}-b\right| \tanh \left(X_{t}-b\right), & X_{t}<b \\ 0, & \text { otherwise. }\end{cases}
$$

Figure 3 shows the graph of the subsidy factor $s_{t}:(-\infty, b] \rightarrow[0,1), s_{t}=-\tanh \left(X_{t}-\right.$ $b$ ), which should still be multiplied by $\left|X_{t}-b\right|$ and the household's individual consumption $C_{t}^{h}$ to obtain the total subsidy payment.

The first level $a$ can be positive or negative. For example, an aggressive stabilization policy might be to set $a=0.03$ implying that the subsidy regime becomes active if the GDP growth rate drops below $+3 \%$. If instead $a=-0.01$, the subsidy takes effect only after the growth rate has fallen below $-1 \%$. In both cases, as already mentioned, the subsidy is awarded until $X_{t}$ increases to $b$. A justification for the asymmetry between the on and off triggers is that the subsidy typically gets activated relatively late during a downturn because of recognition, decision, and implementation lags, but should remain active until strong growth is assured again.

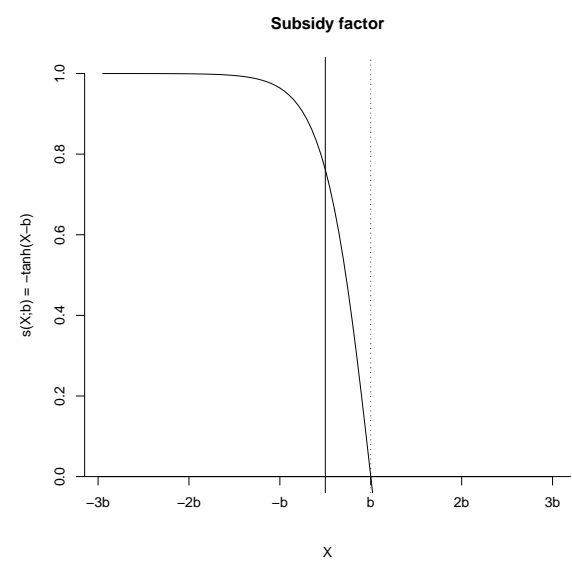

Fig. 3 Graph of the subsidy factor $s_{t}=-\tanh \left(X_{t}-b\right)$. To obtain the actual subsidy payment this should be multiplied by $\left|X_{t}-b\right|$ and the household's individual consumption $C_{t}^{h}$.

\subsection{The tax reduction policy}

The tax reduction policy has the objective to alleviate the tax burden of the private sector in general, so it applies to both firms and households. Therefore, in this policy we vary endogenously the income tax rate on both personal income and corporate income. 
For the household this has the same effect as the subsidy scheme, except the stimulus is now based in income instead of consumption.

In the case of the firm, the tax reduction scheme is meant to compensate the firm for an increase in production costs. These costs consist of labour costs and the costs of acquiring new capital (investments).

We implement the tax reduction scheme using a similar approach as the one above for the consumer subsidy. We use the same on/off switches conditional on the GDP growth rate, and the reduction in the tax rate is given by almost the same formula (but note the reversed sign):

$$
T_{t}= \begin{cases}\max \left\{0, \tau+\left|X_{t}-b\right| \tanh \left(X_{t}-b\right)\right\}, & X_{t}<b \\ \tau, & \text { otherwise. }\end{cases}
$$

Here $\tau=0.05$ is the default tax rate on households' personal income and firms' corporate income. $^{2}$ This results in an income tax rate $T_{t} \in\left(\tau-\left|X_{t}-b\right|, \tau\right)$, where $X_{t}$ is the GDP growth rate.

\subsection{Experimental design}

In this subsection we describe how we set up the computational experiments. In the model, one iteration represents one business day ( 1 week $=5$ days, 1 month $=20$ days, 1 year $=240$ days). All our simulation runs have a length of 6000 iterations (300 months), consisting of an initial transient of 1000 iterations (50 months) that is ignored in the analysis of the experiment. Hence, all results are based on 250 months. Furthermore, all results are based on comparisons of distributional outcomes, since single runs will not provide generic results. To obtain statistically significant results we performed 10 batch runs for each scenario and then perform a Monte Carlo analysis. All plots show the Monte Carlo mean and the first and third quartile of the Monte Carlo distribution across the batch runs. Table 2 gives the default parameter values that are used in the computational experiments.

We consider an energy shock over a pre-determined time interval $\left[T_{\text {start }}, T_{\text {end }}\right]$. After the transient phase, we run the model for 12 more months before starting the energy shock at $T_{\text {start }}=12$. After the energy crisis has ended, at $T_{\text {end }}=24$, we run the model till $t=250$ months in order to analyze the legacy of the shock.

Figure 2 shows the time profile of the energy shock experiment. The choice of the profile is motivated by the empirical evidence as shown in Figure 1. There are $n$ consecutive instantaneous price increases between $T_{\text {start }}$ and $T_{\text {end }}$, at equidistant time intervals, and an instantaneous decrease of intensity $(1+\pi)^{-n}$ at $t=T_{\text {end }}$. This brings the price back to its pre-shock level, if no other influences would have

\footnotetext{
${ }^{2}$ Note that the default tax rate of $5 \%$ is relatively low compared to empirical rates, but this should be seen in the model context where the tax rate refers to unemployment insurance contributions only, which in Germany are currently at $2.8 \%$.
} 
affected the price in the meantime. However, over the course of the energy crisis, the process of technological innovation continues in the background so the capital goods price is updated as usual. Hence, the price level of the investment goods at the end of the crisis will typically differ from the price level at the beginning of the crisis.

\section{Simulation results}

In this section we present simulation results for four scenarios:

1. Benchmark scenario: no energy shocks occur. This defines the default model behavior.

2. Energy shock only scenario: an energy crisis occurs, without any stabilization policy. This provides a baseline to compare the effectiveness of the stabilization policies.

3. Consumer subsidy scenario: an energy crisis occurs, and a stabilization policy is implemented by a consumer subsidy scheme.

4. Tax reduction scenario: an energy crisis occurs, and a stabilization policy is implemented by a tax reduction scheme.

Table 3 summarizes the computational settings in each scenario.

\subsection{Results per scenario}

\section{Scenario 1: Simulations for the Benchmark Scenario}

We recall the benchmark results in Figure 4: GDP settles down to a stable growth path of $2.5 \%$ p.a., which equals the rate of technological progress. Total investments grow at the same rate. The price of capital goods shows a typical staircase pattern due to the incremental technological progress (see Fig. 4c). The budget deficit as a percentage of GDP is on average above the threshold of the Maastricht criterium $(-0.03)$.

\section{Scenario 2: Effects of Energy Shocks without Countermeasures}

We now consider a situation in which there are energy shocks but no active policy measures to counter the negative effects on the economy.

In Figure 5a (column 1) we introduce a mild energy shock of $1 \%$ at $t=12$. At $t=24$ months there is a downward shock of $12 \%$. Such low intensity shocks to the capital goods price hardly affects the economy. 
A stronger energy crisis is shown in Figure 5b (column 2), with multiple shocks of $2.5 \%$. This results in a more pronounced energy spike with significant effects on key macroeconomic variables such as GDP, investments and the unemployment rate (not shown).

The final case is the one shown in Figure $5 \mathrm{c}$ with multiple shocks of 5\%, one per month. Here finally we have the signature of a true energy crisis, where at its peak capital goods cost twice as much as they did at the start of the crisis. The downward effect on GDP is considerable with a $-20 \%$ decline. Investments also decline sharply during the crisis, but then rebound to original levels as soon as the energy prices return to normal levels.

Note that after the energy crisis there is an aftershock which is smaller than the main event. This is due to the overshooting that follows immediately after the crisis ends, when energy prices drop down to normal levels. This results in overconsumption and overinvestment, i.e. a build up of excess production capacity. After the secondary small correction, the economy settles down on its long-term growth path which is determined by the rate of technological progress ( $2.5 \%$ by default), see row 3.

In Tables 4 and 5 we quantify the relationship between the magnitude of the shocks and the mean and standard deviations of the GDP growth rate and the deficit/GDP fraction, respectively.

For increasing values of the shock intensity parameter $(\pi=0.01,0.025,0.05)$ the short-term fluctuations of GDP growth rates increase dramatically, displaying swings between $-22 \%$ to $+40 \%$ for a shock intensity of 5\% (see Fig. 6). Another effect is that the budget deficit shows more volatility, with extreme deficits of $-12 \%$ or surplusses of $+25 \%$ of GDP.

\section{Scenario 3: Energy Shock with the Consumer Subsidy}

The results for the consumer subsidy scheme are shown in Figure 7 (left panel). The on/off triggers are set to $a=b=0.03$. The subsidy percentage increases during the energy crisis to average levels of $0.1-0.8 \%$ of the monthly consumption expenditure. Note that since the government only adjusts its policy once a year, at the end of the calendar year, the monthly data shown in the plot displays stepwise jumps with a yearly frequency.

\section{Scenario 4: Energy Shock with the Tax Reduction}

Figure 7 (right panel) shows the results for the tax reduction stabilization scheme. The tax reduction results in a tax rate of $4.2-4.7 \%$ during the crisis, and $4.4-$ $4.8 \%$ immediately afterwards (months $25-85$, includes the aftershock), due to the 
persistence in the policy. Similar to the subsidy scenario, the tax reduction policy also has a yearly frequency, and there is a lag in the government response time.

\subsection{Comparison between scenarios}

In Figure 8 we make a direct comparison between the energy shock-only scenario and the stabilization scenarios in terms of the ratio of nominal GDP and the the ratio of total investments with respect to the energy shock-only results (all scenarios use $\pi=0.025$ ). Three main results follow from these simulations.

\section{Result 1}

We consider the GDP ratios in Fig. 8 (row 1). The mean GDP levels in the stabilization scenarios are consistently higher than in the energy shock-only scenario (the mean is consistently above the 1.0 ratio). This shows that the demand stimulus of both stabilization policies results in an upward shift of the nominal value of GDP.

\section{Result 2}

We consider the investment ratios in Fig. 8 (row 2). During the energy crisis, the mean investments in both stabilization scenarios are higher than in the shock-only scenario. However, this is only true during the crisis, not before or after it. This means that the stabilization policies have their intended effect to stimulate consumption and investments, either directly or indirectly.

\section{Result 3}

The tax reduction policy yields slightly better results than the consumer subsidy policy with respect to stimulating investments, since the former affects both consumers and firms, while the latter only affects consumers. Thus, the tax reduction policy is in fact the more effective policy, if only due to the choice of having it apply to both personal income and corporate income taxes. Furthermore, the consumer subsidy only has an indirect stimulating effect on investments through the demand channel, while the tax reduction for firms has a more direct effect on stimulating investments. 


\subsection{Short-term versus long-term effects of energy shocks}

In this section we compare the four scenarios discussed above by analysing their short- and long-term effects.

\subsubsection{Short-term effects}

The short-run effects are calculated across months $0-75$, which includes the crisis and its aftershock. The results are shown in the left panels of Figs. $9-10$ and Tables 4-5 (see appendix) report the summary statistics for resp. the distributions of the GDP growth rate and the Government deficit/GDP ratio, across all scenarios.

\section{Result 4: GDP growth}

Fig. 9 and Table 4 (left panel) show an increase in short-run volatility of the GDP growth rate in the energy shock scenario ( $\sigma=3.772$ vs. 1.551$)$, which is due to the overconsumption/overinvestment bubble in the short-run. Compared to the benchmark scenario the energy shock obviously causes increased fluctuations in the absence of any stabilization.

The subsidy policy however aggrevates the upswing after the crisis since the government provides easy money that enters the economy through the consumption of households and then leads to an overheating effect. Hence the higher standard deviation $(\sigma=3.718)$. The tax reduction policy results in smaller upswings and downswings than the subsidy regime, resulting in a lower short-run volatility $(\sigma=$ 3.26).

\section{Result 5: Deficit/GDP ratio}

In Fig. 10 and Table 5 (left panel) we observe that in the energy shock-only scenario the short-run volatility of the deficit/GDP ratio increases $(\sigma=2.482$ vs. 1.904$)$. The subsidy policy raises the volatility of the budget deficit/GDP ratio somewhat more than the energy shock itself $(\sigma=2.79)$ while the tax reduction scheme also raises it $(\sigma=2.673)$, but somewhat less than in the subsidy scenario.

\subsubsection{Long-term effects}

The long-run effects are calculated across months $225-250$, and shown in the right panels of Figs. 9 - 10, with Tables $4-5$ (right panels) reporting the summary statistics. 


\section{Result 6: GDP growth}

The energy shock and subsidy scenarios have lower average long-run growth rates than in the benchmark scenario ( 1.413 and 1.17 vs. 1.61$)$, while the tax reduction scenario has a higher growth rate than the benchmark scenario (1.874). The difference in distribution between the tax and subsidy scenarios can be shown to be statistically significant. ${ }^{3}$ Hence, there are long lasting effects of energy shocks in the case of a subsidy policy, but not in the case of a tax reduction policy, leading to a permanent loss in economic value in the long run.

\section{Result 7: Deficit/GDP ratio}

The long-run values of the deficit-to-gdp ratio are all around $\mu=-4.5 \pm 1.5$. The long-run volatility in the energy shock scenario is lower than in the benchmark $(\sigma=1.024$ vs.1.392), while for the subsidy scenario it is slightly higher (1.743). The tax scenario is inbetween these two values (1.601). The high long-run volatility the subsidy scenario can be explained by the lower long-run average growth rates, as shown in result 6 . The Government finances deteriorate more than in the tax reduction scenario.

\subsection{Discussion}

A tentative explanation for the long-term memory effect on the growth rates is that there exists a 'permanent loss of time' effect. The argument can be sketched as follows. The employees' specific skill levels increase when using a new technology. If firms do not invest, the technological progress embodied in newly produced capital goods does not get incorporated into their existing capital stock and workers' specific skills do not get a chance to be augmented (there is no learning-by-doing). This delay in augmenting the specific skills reflects a permanent "loss in time", and has reverbating effects on the entire future development of the economy.

In the case of the subsidy scheme, firms are only indirectly stimulated to invest. Therefore, during the crisis period, firms reduce investments and despite the overshooting and overheating of the economy, this does not compensate for the structural loss in time. It is merely the burning of easy money provided by the government through the subsidy scheme to households, instead of money being used for structural investments in both physical capital and human capital.

Immediately following the crisis there is overinvestment and a corresponding build-up of excess production capacity, but without the employees' specific skill levels to work effectively with the new technology, the higher potential productiv-

\footnotetext{
${ }^{3}$ Results of Wilcoxon tests are shown in the appendix.
} 
ity of the physical capital cannot be turned into effective productivity due to the complementarity between labour and capital.

In the case of the tax reduction scheme, however, firms receive a more direct stimulus to invest. Hence, they reduce the investments in both physical and human capital less during the crisis and the resulting "loss of time" incurred by the economy is reduced.

A final conclusion of this argument would then be that in order to support longrun growth, policy measures are needed that directly stimulate investments, in both human and physical capital, instead of stimulating consumption and hoping that this will indirectly affect investments through the demand channel.

\section{Conclusions}

We have studied the out-of-equilibrium dynamic response of an artificial macroeconomy to external disturbances such as an energy crisis. A bubble can occur in the real sector when at the end of the crisis prices decrease drastically leading to overconsumption and overinvestment on the short-term. A stabilization policy can then dampen the magnitude of such fluctuations and reduce the overshooting effect.

We have made a direct comparison between two types of macroeconomic stabilization policies: a consumer subsidy that only affects households, and a tax reduction scheme that affects both households and firms.

The stabilization scenarios are compared to the baseline energy shock-only scenario in terms of the ratios of nominal GDP and total investments. Three main results follow from such a comparison.

First, over the entire length of the simulation, the mean GDP levels in the stabilization scenarios are consistently higher than in the energy shock-only scenario.

Second, during the energy crisis mean investments are higher in the stabilization scenarios than in the shock-only scenario. However, this only holds during the crisis, not before or after it, and means that the stabilization policies have their intended effect to stimulate consumption and investments, either directly or indirectly.

Third, the tax reduction policy yields slightly better results than the consumer subsidy policy with respect to stimulating investments. This can be explained by the observation that the tax reduction policy applies to both personal income and corporate income tax rates, so it affects both consumers and firms. Furthermore, the consumer subsidy only has an indirect stimulating effect on investments through the demand channel, while the tax reduction for firms has a more direct effect on investments.

Furthermore, we are able to distinguish between the short- and long-term effects of the stabilization policies. On the short run, the subsidy scheme aggrevates the upswing immediately following the crisis since the government provides easy money that enters the economy through the consumption of households and then leads to an overheating effect. The tax reduction scheme results in smaller fluctuations than the subsidy regime, with slightly lower variance in the short-run GDP growth rates. 
On the long run, the subsidy scenario shows significantly lower average growth rates than the tax reduction scenario, while in the latter the growth rates do not significantly differ from those of the benchmark. Hence, there are long-lasting effects of energy shocks in the case of a subsidy policy but not in the case of a tax reduction policy.

A tentative explanation of this long-memroy effect is that by postponing investment decisions during the crisis, firms are essentially foregoing the time to allow their workers to learn on-the-job so that when the crisis is over they are lagging behind in knowledge they could have potentially obtained, resulting in a lower effective productivity.

A final conclusion is that in order to support long-run growth, policy measures are needed that stimulate investments directly, both in human and physical capital, instead of stimulating consumption and hoping that this will indirectly affect the investments through the demand channel.

\section{Acknowledgement}

This work was carried out in conjunction with the EURACE project (EU IST FP6 STREP grant 035086) which is a consortium lead by S. Cincotti (Università di Genova), H. Dawid (Universitaet Bielefeld), C. Deissenberg (Université de la Méditerranée), K. Erkan (TUBITAK National Research Institute of Electronics and Cryptology), M. Gallegati (Università Politecnica delle Marche), M. Holcombe (University of Sheffield), M. Marchesi (Università di Cagliari), C. Greenough (STFC - Rutherford Appleton Laboratory).

\section{References}

Allen, F., Michaely, R., 2004. Corporate finance: Handbook of the Economics of Finance. Amsterdam: North-Holland, Ch. Payout policy, pp. 337-429.

Brav, A., Graham, J. R., Harvey, C. R., Michaely, R., 2005. Payout policy in the $21^{\text {st }}$ century. Journal of Financial Economics 77 (3), 483-527.

Dawid, H., Gemkow, S., Harting, P., Kabus, K., Neugart, M., Wersching, K., 2008. Skills, innovation, and growth: An agent-based policy analysis. Journal of Economics and Statistics 228, 251-275.

Dawid, H., Gemkow, S., Harting, P., Neugart, M., 2009. On the effects of skill upgrading in the presence of spatial labor market frictions: An agent-based analysis of spatial policy design. Journal of Artificial Societies and Social Simulation $12(4), 5$.

URL : http://jasss.soc.surrey.ac.uk/12/4/5.html

Deaton, A., 1991. Saving and liquidity constraints. Econometrica 59, 1221-1248.

Deaton, A., 1992. Houshold saving in LDCs: Credit markets, insurance and welfare. Scandinavian journal of Economics 94, 253-273. 
Deissenberg, C., van der Hoog, S., Dawid, H., 2008. Eurace: A massively parallel agent-based model of the European economy. Applied Mathematics and Computation 204, 541-552.

Hillier, F., Lieberman, G., 1986. Introduction to Operations Research. Holden-Day. van der Hoog, S., Deissenberg, C., Dawid, H., 2008. Production and finance in EURACE. In: Schredelseker, K., Hauser, F. (Eds.), Complexity and Artificial Markets. Vol. 614 of Lecture Notes in Economics and Mathematical Systems. Springer Berlin Heidelberg, pp. 147-158.

Kahneman, D., Tversky, A., 1979. Prospect theory: An analysis of decision under risk. Econometrica 47 (2), 263-292.

Nagle, T., 1987. Strategy and Tactics of Pricing. Prentice Hall.

Raberto, M., Teglio, A., Cincotti, S., 2008a. Integrating real and financial markets in an agent-based economic model: An application to monetary policy design. Computational Economics 32 (1), 147-162.

Raberto, M., Teglio, A., Cincotti, S., 2008b. Prospect theory behavioral assumptions in an artificial financial economy. In: Schredelseker, K., Hauser, F. (Eds.), Complexity and Artificial Markets. Vol. 614 of Lecture Notes in Economics and Mathematical Systems. Springer Berlin Heidelberg, pp. 55-66.

Rotemberg, J., Woodford, M., 1996. Imperfect competition and the effects of energy price increases on economic activity. Journal of Money, Credit and Banking 28, 549-577. 

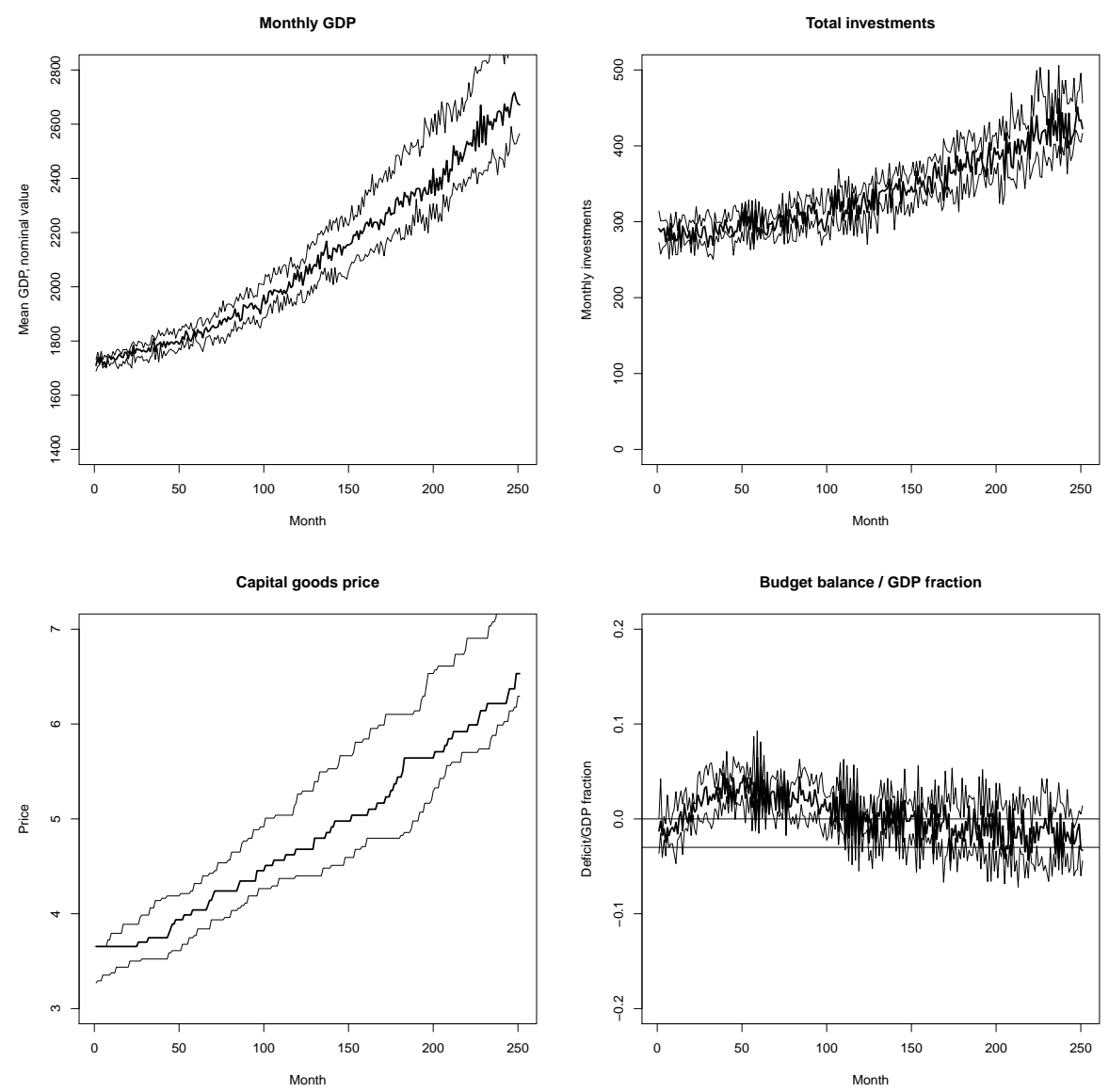

Fig. 4 Benchmark scenario. All results are Monte Carlo means across 10 runs. Black line: MonteCarlo mean, dotted lines: $1 s t-3 r d$ quartiles. (a) Monthly GDP in nominal values. (b) Total monthly investments. (c) Capital goods price. (d) Government finances: the budget deficit as a percentage of GDP $(0.01$ means $1 \%)$. The horizontal line at -0.03 is the Maastricht criterium. 

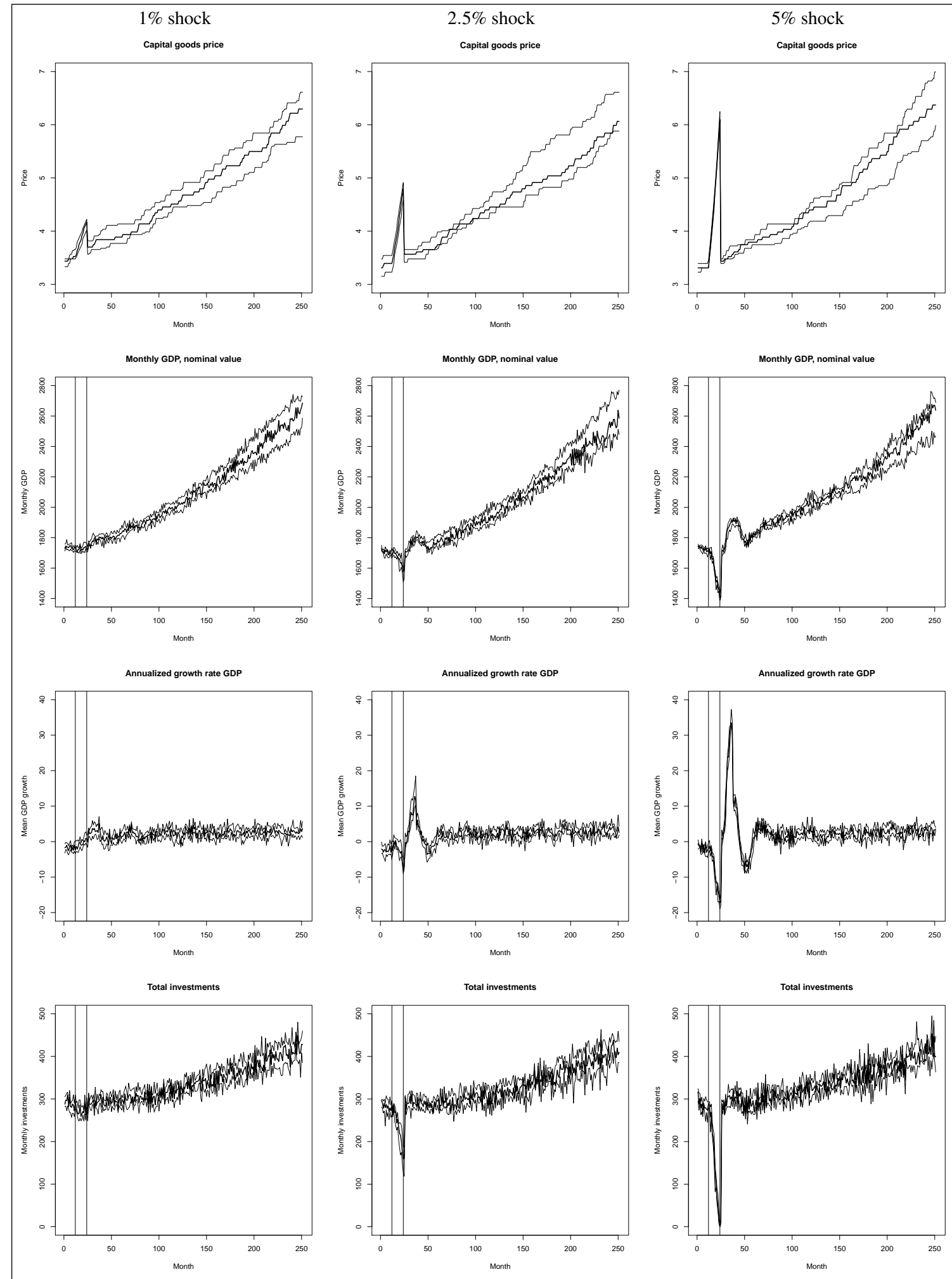

Fig. 5 Results for the energy shock scenario. Vertical lines indicate the energy crisis. Parameters: duration $d=240$, periodicity $\Pi=20$, intensity $\pi=0.01,0.025,0.05$. Row 1 : Capital goods price. Row 2: GDP nominal value. Row 3: GDP growth rate. Row 4: Total investments. 

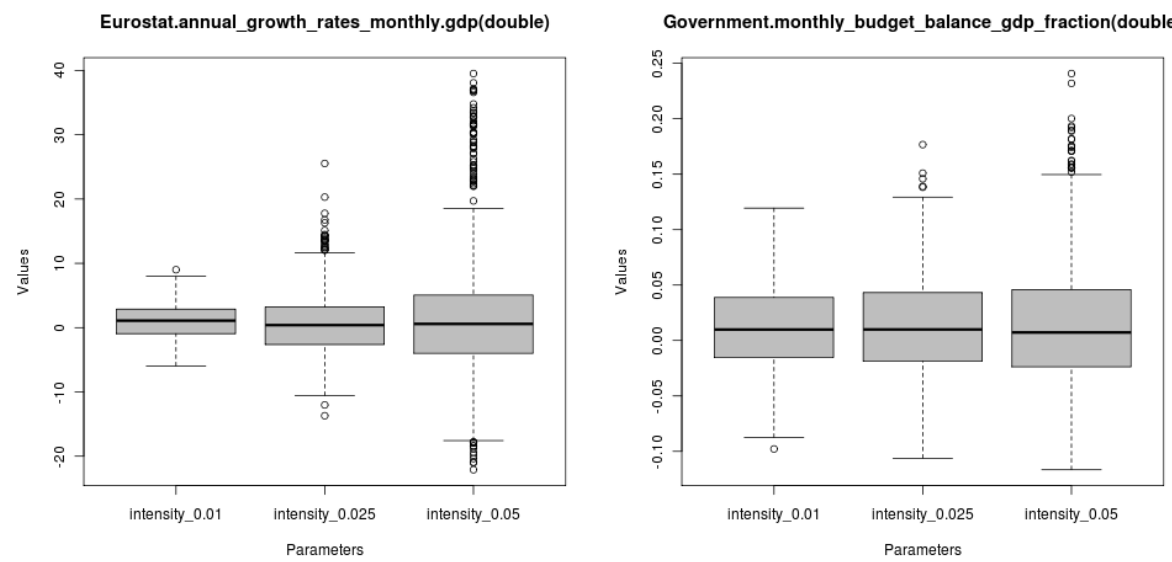

Fig. 6 Comparison for different values of the shock intensity: $\pi=0.01,0.025,0.05$. Left: annualized GDP growth rates in months $0-75$ (includes the crisis and its aftershock). Right: the effect on government finances due to the shock (monhtly budget deficit as \% of GDP).
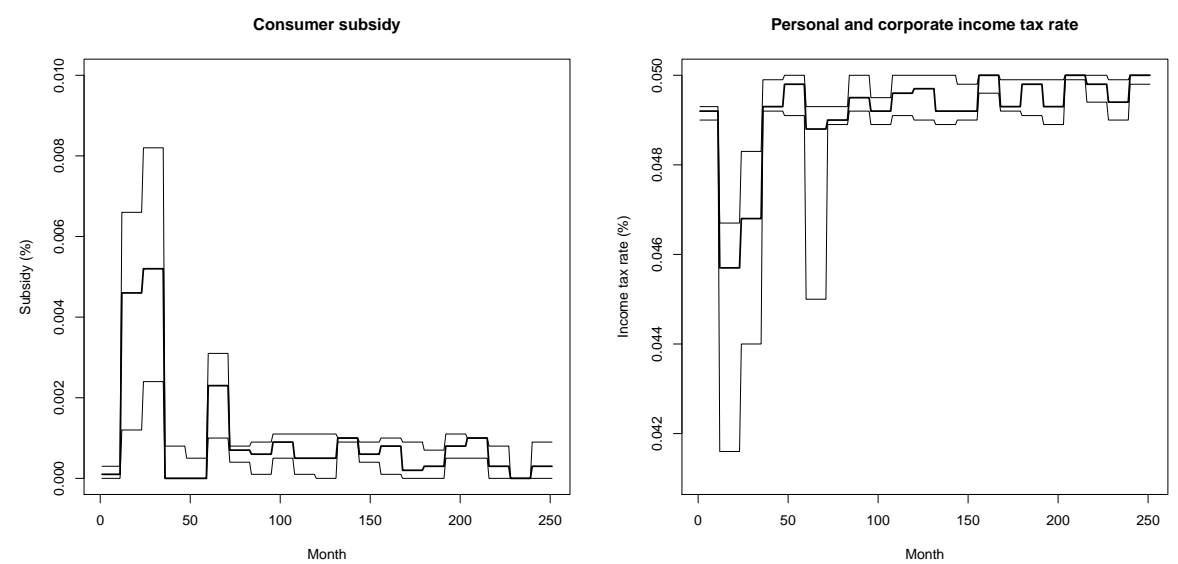

Fig. 7 Results for the energy shock scenario with the consumer subsidy scheme (left panel) and the tax reduction scheme (right panel). Parameters: $\pi=0.025, a=b=0.03$. The plot shows the stepwise yearly adjustments of the policy parameter. 


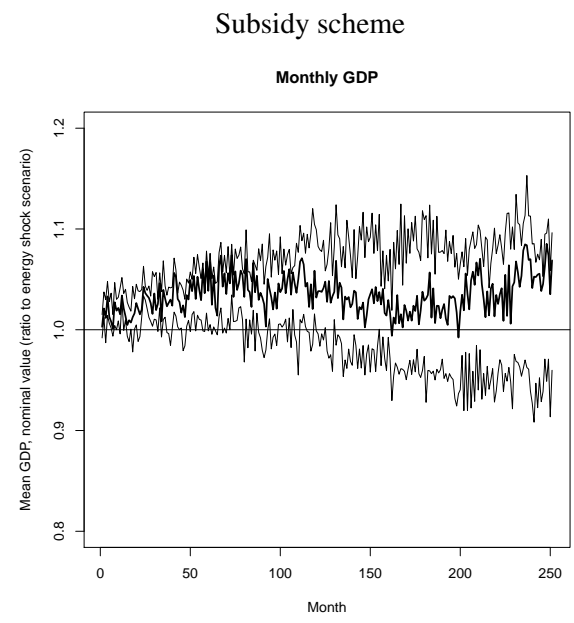

Tax scheme
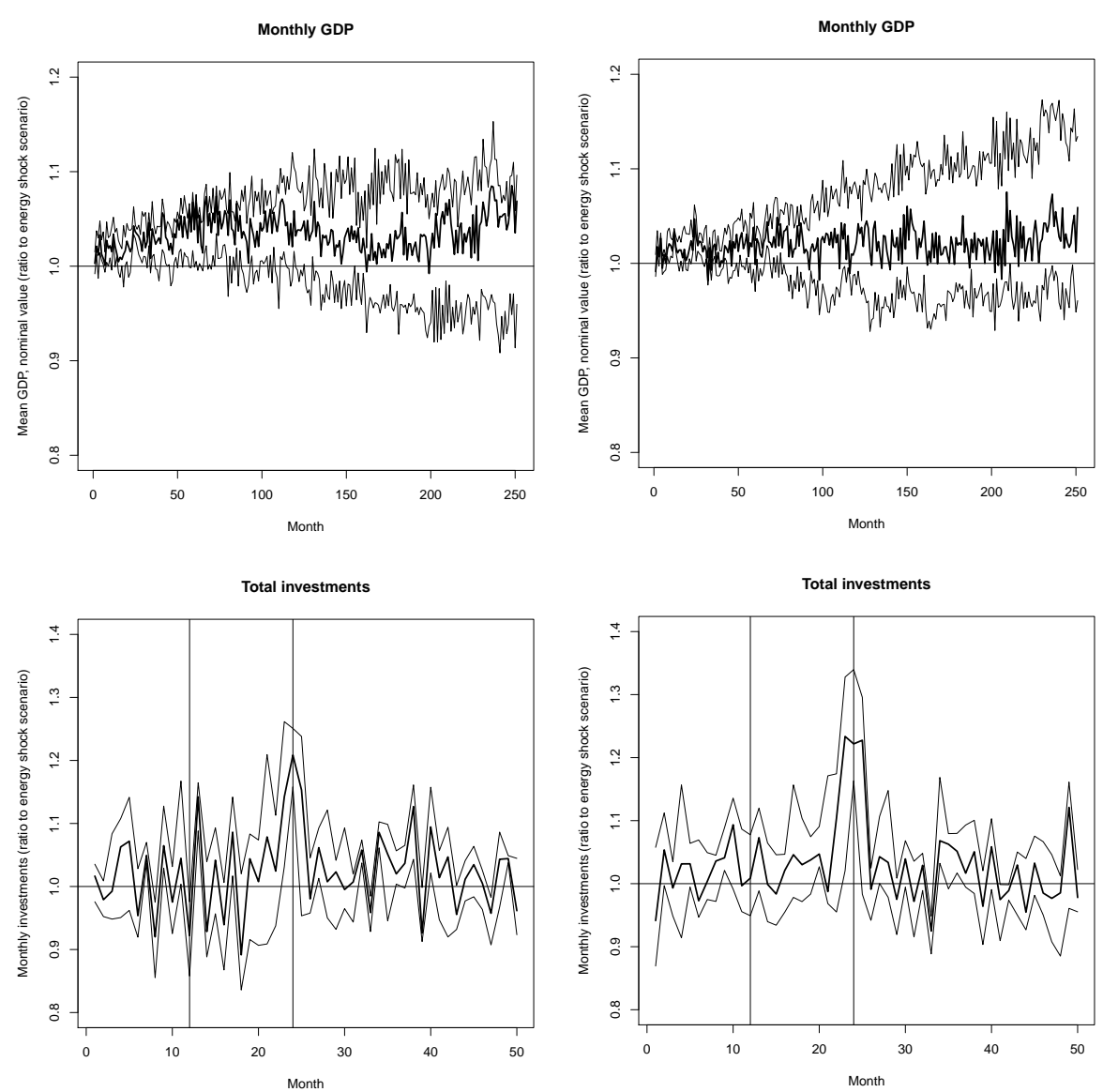

Fig. 8 Comparison between the energy shock-only scenario and the stabilization scenarios in terms of the ratio of nominal GDP and total investments. Vertical lines indicate the energy crisis. 

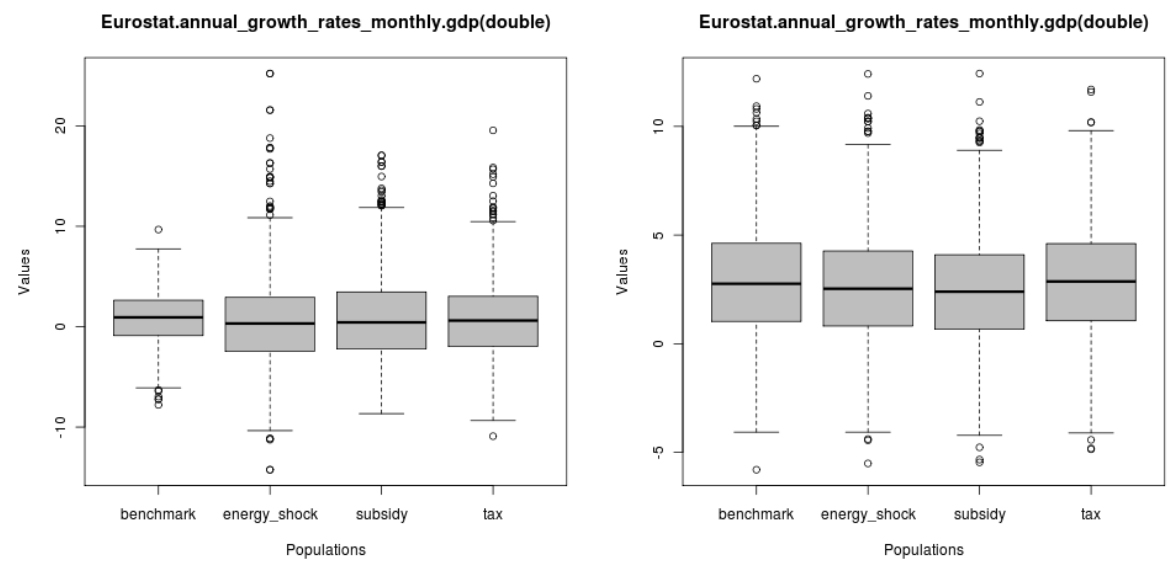

Fig. 9 Comparison of short- and long-run effects on GDP growth rates. Left panel: short run, months $0-75$. Right panel: long run, months $100-250,6$ years after the crisis has ended.
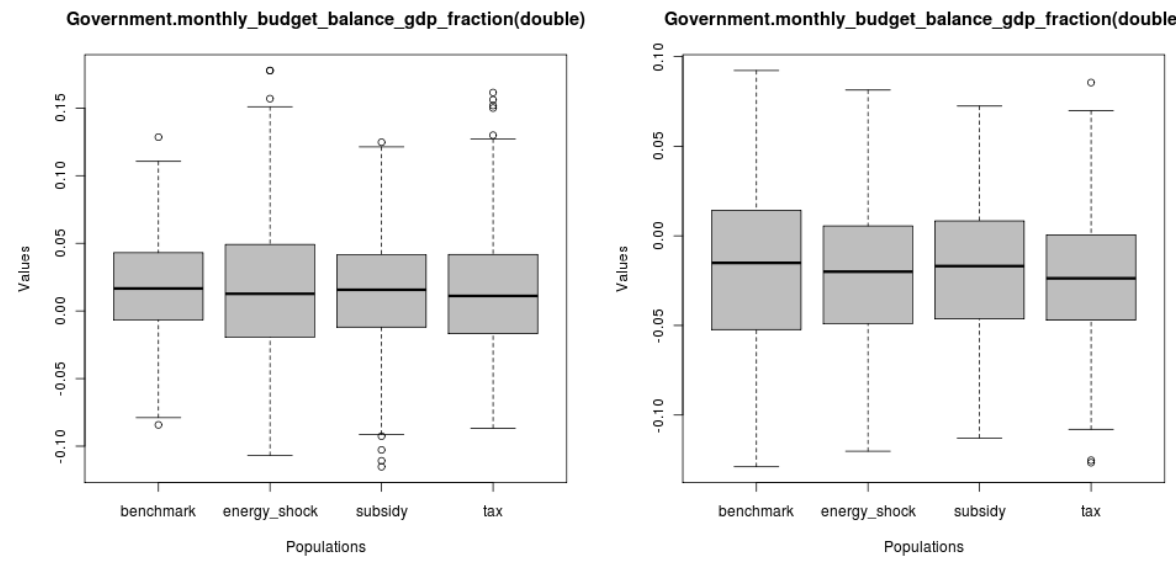

Fig. 10 Comparison of short- and long-run effects for Government monthly budget deficit across the four scenarios. Left panel: short run, months $0-75$. Right panel: long run, months $225-250$. 
Table 2 Parameter values

\begin{tabular}{lcll}
\hline \hline Name & Symbol Values & Description \\
\hline Energy crisis duration & $d$ & 240 & Duration of the energy crisis in days. \\
Energy shock intensity & $\pi$ & $\{0.01,0.025,0.05\}$ & Percentage energy price change for a single shock. \\
Periodicity of shocks & $\Pi$ & 20 & Periodicity of the shock in days. \\
Income tax rate & $\tau$ & 0.05 & Tax rate on personal and corporate income. \\
Innovation probability & $\gamma^{i n v}$ & 0.10 & Probability that an innovation is successful. \\
Technological progress & & 0.025 & Increase in productivity in case of a succesful innovation. \\
Capital price mark-up & $p_{t, c}$ & 0.025 & Price increase of capital goods in case a succesful innovation occurs. \\
Energy price mark-up & $\pi$ & $\{0.01,0.025,0.05\}$ & Price increase of capital goods in case of an energy price increase. \\
\hline
\end{tabular}

Table 3 Overview of the computational settings for the scenarios.

\begin{tabular}{ll}
\hline \hline Scenario & Parameter set \\
\hline Benchmark & $\pi=0, T=0.05$ \\
Energy shock & $\pi=0.01,0.025,0.05, T=0.05$ \\
Consumer subsidy & $\pi=0.025, T=0.05, a=b=0.03$ \\
Tax reduction & $\pi=0.025, a=b=0.03$ \\
\hline \hline
\end{tabular}

Table 4 Summary statistics for short-term (months $0-75$ ) and long-term (months $225-250$ ) GDP growth factors.

\begin{tabular}{l|llll}
\hline & \multicolumn{2}{|c}{ Short-term } & \multicolumn{2}{c}{ Long-term } \\
& Mean & Std. & Mean & Std. \\
\hline Benchmark & -0.723 & 1.551 & 1.61 & 0.938 \\
Energy shock: & & & & \\
$\pi=0.01$ & -0.668 & 1.685 & 1.085 & 0.958 \\
$\pi=0.025$ & -1.069 & 3.772 & 1.413 & 0.821 \\
$\pi=0.05$ & -0.046 & 10.382 & 1.664 & 1.184 \\
Subsidy & -0.646 & 3.718 & 1.17 & 0.976 \\
Tax & -0.847 & 3.26 & 1.874 & 1.068 \\
\hline
\end{tabular}


Table 5 Summary statistics for short-term (months $0-75$ ) and long-term (months $225-250$ ) deficit/GDP ratios (\%).

\begin{tabular}{l|llll}
\hline & \multicolumn{2}{|c}{ Short-term } & \multicolumn{2}{c}{ Long-term } \\
& Mean & Std. & Mean & Std. \\
\hline Benchmark & -0.130 & 1.904 & -4.571 & 1.392 \\
Energy shock: & & & & \\
$\pi=0.01$ & -1.029 & 1.465 & -4.362 & 1.228 \\
$\pi=0.025$ & -1.043 & 2.482 & -4.582 & 1.024 \\
$\pi=0.05$ & -2.017 & 3.54 & -3.933 & 1.167 \\
Subsidy & -0.307 & 2.79 & -4.064 & 1.743 \\
Tax & -0.899 & 2.673 & -4.473 & 1.601 \\
\hline
\end{tabular}


Listing 1 Economic activities taking place on a hierarchy of time-scales with yearly, monthly, weekly and daily activities.

On 1 st day of calender year:

Government :

- announce new policies

On 1 st day of calender month:

IGFirm :

- set new price for capital goods

On 1 st day of subjective month:

Firms :

- decide production plan

- determine input demand for capital and labour

- determine external financial needs for production

- visit credit market: ask for credit loans with banks

- visit financial market: issue new shares

- if credit rationed: rescale production

- visit capital goods market

- visit labour market

- produce output

- distribute output to malls

Households :

- if employed: receive wage

- receive subsidy based on previous month consumption

- determine consumption budget for upcoming month

On 1 st day of subjective week:

Households :

- visit consumption goods market

Every day:

Firms :

- receive revenues from malls

Households:

- visit financial market: reallocate asset portfolio

- if unemployed: visit labour market

Banks :

- receive dividends

- receive loan requests, supply credit to firms

- receive payment account updates

- compute balance sheet (value-at-risk, total credit supply)

Government :

- receive tax revenues

On 20 th (1ast) day of subjective month:

Firms :

- compute revenues, income statement and balance sheet

- pay taxes, dividends

- send data to Eurostat

Households :

- pay taxes

On 20 th (1ast) day of calender month:

Eurostat :

- compute monthly aggregate macrodata and statistics

On last day of calender year:

Eurostat:

- compute yearly aggregate macrodata and statistics

Government :

- compute balance sheet

- set new policies (tax rate, subsidy pct) 


\section{Statistical testing of the long-run effects on GDP growth rates}

In this appendix we test the hypothesis that the long-run GDP growth rate is lower in the energy shock and subsidy scenarios than in the benchmark scenario. More formally, we need to test the hypothesis that the sample mean of the GDP growth rates in one of the three alternative scenarios (energy shock only, energy shock with subsidy, energy shock with tax reduction) is lower than the sample mean in the benchmark scenario. We also have a fourth hypothesis which is that the mean longterm growth rate in the tax scenario is higher than the mean growth rate in the subsidy scenario.

More formally, we use the Wilcoxon test to test if the sample means of two distributions are equal, with these hypotheses:

$$
\begin{aligned}
& \text { H0: } x=y \text {, or } x-y=0, \\
& \text { H1: } x>y \text {, or } x-y>0 .
\end{aligned}
$$

where

$x$ : sample mean of long-run growth rates in the benchmark scenario (using observations $100-250)$.

$y$ : sample mean of long-run growth rates in the alternative scenario (using observations $100-250)$.

Table 6 gives p-values for each pairwise comparison of an alternative scenario to the benchmark scenario. ${ }^{4}$ From this table we conclude the following.

Test 1 has a p-value $p=0.2201$, so we cannot reject the hypothesis that the mean long-run growth rate in the energy shock scenario is equal to the mean longrun growth rate in the benchmark scenario. In test 2 the p-value is $p=0.06563$, so for any significance level $\alpha>6.6 \%$ we can reject the null, and conclude that the mean growth rate in the subsidy scenario is lower than the mean growth rate in the benchmark scenario. However, for $\alpha=5 \%$ we cannot reject the null. Test 3 has a p-value $p=0.6347$, so we cannot reject the hypothesis that the mean in the tax scenario is equal to the mean in the benchmark scenario. Test 4 has a p-value $p=0.03828$, so for any significance level $\alpha>3.9 \%$ we can reject the null, and conclude that the mean in the tax scenario is higher than the mean in the subsidy scenario.

The overall conclusion is thus that the mean long-run growth rate in the subsidy scenario is significantly lower than in the benchmark and tax reduction scenarios. All other comparisons are not statistically significant at reasonable significance levels.

\footnotetext{
${ }^{4}$ For a given significance level $\alpha$, the null hypothesis is rejected if $p \leq \alpha$, for $p>\alpha$ we do not reject the null.
} 
Table 6 Overview of Wilcoxon test results.

\begin{tabular}{ll}
\hline \hline Scenario & $\mathrm{p}$-value \\
\hline Energy shock only & 0.2201 \\
Consumer subsidy & 0.06563 \\
Tax reduction & 0.6347 \\
Tax vs subsidy & 0.03828 \\
\hline \hline
\end{tabular}

